\title{
Correlation of Cesarean rates to maternal and infant mortality rates: an ecologic study of official international data
}

\author{
Fernando Madalena Volpe ${ }^{1}$
}

Suggested citation Volpe FM. Correlation of Cesarean rates to maternal and infant mortality rates: an ecologic study of official international data. Rev Panam Salud Publica. 2011;29(5):303-8.

ABSTRACT Objective. To correlate international official data on Cesarean delivery rates to infant and maternal mortality rates and low weight-at-birth rates; and to test the hypothesis that $\mathrm{Ce}^{-}$ sarean rates greater than 15\% correlate to higher maternal and infant mortality rates.

Methods. Analyses were based on the most recent official data (2000-2009) available for 193 countries. Exponential models were compared to quadratic models to regress infant mortality rates, neonatal mortality rates, maternal mortality rates, and low weight-at-birth rates to Cesarean rates. Separate regressions were performed for countries with Cesarean rates greater than $15 \%$.

Results. In countries with Cesarean rates less than 15\%, higher Cesarean rates were associated to lower infant, neonatal, and maternal mortality rates, and to lower rates of low weightat-birth. In countries with Cesarean rates greater than 15\%, Cesarean rates were not significantly associated with infant or maternal mortality rates.

Conclusions. There is an inverse exponential relation between countries' rates of Cesarean deliveries and infant or maternal mortality rates. Very low Cesarean rates (less than 15\%) are associated with poorer maternal and child outcomes. Cesarean rates greater than $15 \%$ were neither correlated to higher maternal nor child mortality, nor to low weight-at-birth.

Key words Infant mortality; maternal mortality; neonatal mortality; Cesarean section; birth weight.

In 1985, the World Health Organization (WHO) held a Joint International Conference on Appropriate Technology for Birth in Fortaleza, Brazil. The conference resulted in several recommendations for proper prenatal and birth care, among which was stated that since the countries with the lowest perinatal mortality rates had Cesarean-section delivery rates below 10\%, there would be "no justification in any specific geographic

\footnotetext{
1 Research Management, Hospital Foundation of Minas Gerais (FHEMIG), Belo Horizonte, Minas Gerais, Brazil. Send correspondence to Fernando Volpe, fernando.volpe@fhemig.mg.gov.br
}

region to have more than $10 \%-15 \%$ Cesarean section births" (1).

Notwithstanding, Cesarean rates have risen considerably in the last 25 years, all over the world, for a number of supposed reasons (2-4). In underdeveloped countries, the low incidence of Cesarean births is considered an indicator of poor access to birth care. Thus, its increase would be desirable, and hypothetically, would be accompanied by decreasing perinatal morbidity/mortality. However, in developing and developed countries, the reasons for this rise do not seem linked to increased access to birth care, but rather related to an increase in elec- tive and subjective use of Cesareans, possibly reflecting patient and/or doctor preference (3, 5-10).

Recent studies in Latin America (11), Asia (12), and Canada $(13,14)$ have consistently shown that individual perinatal risks are elevated, particularly for Cesarean deliveries with no medical indication, for both mother and newborn, when compared to vaginal deliveries. However, from a public health perspective, there is still uncertainty as to what rate of Cesarean deliveries is desirable $(15,16)$. Is there an association between elevated national Cesarean rates and higher infant and maternal mortality? 
What is the optimal rate of Cesareans that could be officially adopted and recommended, and on what grounds?

The aims of this study are to: (a) correlate international official data on Cesarean delivery rates to infant and maternal mortality rates, and to low weight-at-birth rates (LWR); and (b) test the hypothesis that Cesarean rates over $15 \%$ correlate to higher maternal and infant mortality rates.

\section{MATERIALS AND METHODS}

This study used an ecologic design based on the most recently available, annual, official data reported by 193 countries to WHO (17).

The predictor variable was the Cesarean rate $(\mathrm{CR})$. The dependent variables were: infant mortality rate (IMR), neonatal mortality rate (NMR), maternal mortality rate (MMR), and LWR.

IMR refers to the probability of dying before 1 year of age per 1000 live births. The 2008 IMR was available for all countries. NMR is defined as the number of deaths during the first 28 completed days of life per 1000 live births in a given year or other period. The 2008 NMR was available for all countries. MMR is the annual number of female deaths from any cause related to or aggravated by pregnancy or its management (excluding accidental or incidental causes) during pregnancy and childbirth or within 42 days of termination of pregnancy, irrespective of the duration and site of the pregnancy, per 100000 live births, for a specified year. The most recent MMR data available during 2000-2009 was considered. LWR is defined as the proportion of living newborns under $2500 \mathrm{~g}$. The most recent LWR data during 20002008 was considered. Cesarean-section rates are the percentage of Cesarean deliveries among all live births, irrespective of cause or indication. The most recent CR data available during 2000-2008 was considered. A detailed methodology of data acquisition by $\mathrm{WHO}$ is presented elsewhere $(15,17)$. In short, infant mortality estimations are based on vital registration (gold standard, more common in more developed countries), sample registration systems, or surveys and census reports where prospective information is not available. Cesarean rate estimations are based on official reports of vital statistics or on representative surveys, as a result of extensive efforts by the Depart- ment of Making Pregnancy Safer/WHO and their collaborators.

Since any variables were normally distributed, and graphical preliminary analyses suggested exponential or quadratic distributions, nonlinear exponential models $\left(y=a \cdot b^{x}\right)$ were compared to quadratic models $\left(y=a+b_{1} x+b_{2} x^{2}\right)$ to regress IMR, NMR, MMR, and LWR to CR. The goodness-of-fit of models was compared using Akaike's Information Criteria (AIC), for which the lowest values represent the best fitness.

\section{RESULTS}

\section{Global statistics}

According to the latest available data, the global median (minimum-maximum) proportion of Cesarean deliveries was $13.8 \%(0.4-41.9)$ ( $n=124$ countries). Median global IMR in 2008 was 21 per 1000 live births $(1-165)(n=193)$; median global NMR was 12 per 1000 (0-61); median global MMR was 44 per $100000(0-1600)(n=169)$; and median LWR was 9\% $(0-34 \%)(n=184)$.

FIGURE 1. Infant mortality rates as a function of Cesarean rates, by country, according to the most recent official data (2000-2009) for 124 countries

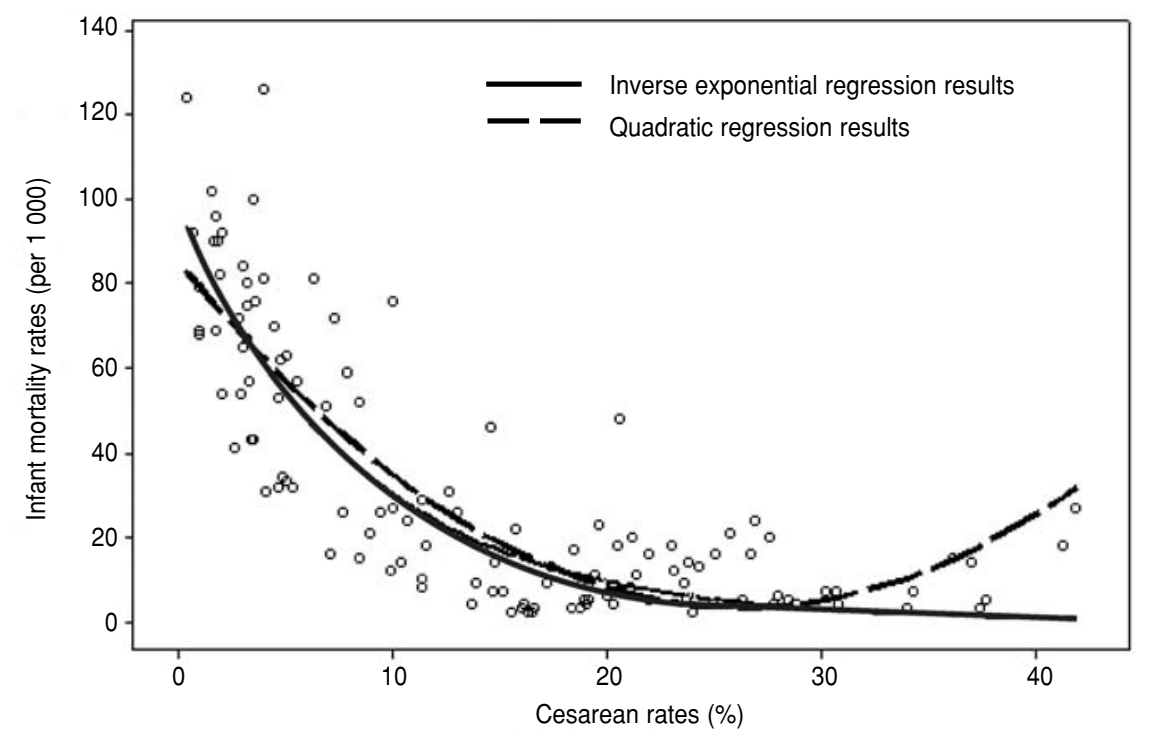

TABLE 1. Comparison of quadratic and exponential models' goodness-of-fit, according to Akaike's criteria (AIC), for infant, neonatal, and maternal mortality rates and low weight-at-birth rates as functions of Cesarean rates, according to the most recent official data (2000-2009)

\begin{tabular}{|c|c|c|c|c|c|c|c|c|}
\hline \multirow[b]{2}{*}{ Model } & \multicolumn{2}{|c|}{ Infant mortality } & \multicolumn{2}{|c|}{ Neonatal mortality } & \multicolumn{2}{|c|}{ Maternal mortality } & \multicolumn{2}{|c|}{ Low weight-at-birth } \\
\hline & $\overline{\text { Adjusted } \mathrm{R}^{2}}$ & AIC & Adjusted $\mathrm{R}^{2}$ & AIC & Adjusted $\mathrm{R}^{2}$ & AIC & Adjusted $\mathrm{R}^{2}$ & AIC \\
\hline Quadratic & $72.1 \%$ & 1008.22 & $70.9 \%$ & 678.86 & $57.6 \%$ & 1443.18 & $30.5 \%$ & 699.17 \\
\hline Exponential & $80.4 \%$ & 966.66 & $70.8 \%$ & 678.27 & $59.4 \%$ & 1437.21 & $31.4 \%$ & 698.70 \\
\hline
\end{tabular}

Infant mortality rates versus Cesarean rates

Complete data were available for 124 countries. No statistical difference existed between median IMR of countries that reported and those that did not report CR (20 vs. 22 per 1 000; KruskalWallis test; $P=0.66$ ). The best fitting equation was an inverse exponential:

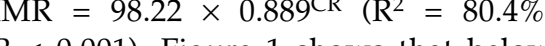
$10 \%-15 \%$ of CR, Cesarean rates pre sented a markedly inverse relation to IMR; and over $10 \%-15 \%$, the curve lost inclination. Neonatal mortality rates followed a similar distribution. Table 1 shows the comparison among quadratic MMR, and LWR as functions of CR.

\section{Maternal mortality ratios versus Cesarean rates}

Complete data were available for 112 countries. Again, no statistical difference existed between median MMR of countries that reported and those that did not 
report Cesarean rates (42 vs. 53 per 100 000; Kruskal-Wallis test; $P=0.78$ ). The best fitting model was an inverse exponential: $\mathrm{MMR}=757.6 \times 0.861^{\mathrm{CR}}(\mathrm{R} 2=59.4 \%$, $P<0.001)$. Figure 2 shows that higher $C R$ correlated to lower maternal mortality ratios when CR was below $10 \%-15 \%$, but the curve lost inclination after that.

\section{Low weight-at-birth versus Cesarean rates}

Complete data were available for 124 countries. No statistical difference existed between median LWR of countries that reported and those that did not report Cesarean rates (9\% vs. 10\%; Kruskal-Wallis test; $P=0.14)$. The best fitting equation was an inverse exponential: $\mathrm{LWR}=12.53 \times 0.860^{\mathrm{CR}}(\mathrm{R} 2=31.4 \%$, $P<0.001)$. Figure 3 shows the inverse correlation between CR and LWR.

\section{Countries with high Cesarean rates}

In order to test the hypothesis, "Cesarean rates over $15 \%$ correlate to higher maternal and infant mortality rates," a series of separate analysis were performed with the 58 countries that presented Cesarean rates $>15 \%$ in the most recent $\mathrm{WHO}$ report available.

No significant correlation was found for IMR (Figure 4) or LWR (data not shown), regarding Cesarean rates. MMR and CR showed a marginally-significant positive correlation $(P=0.08)$, when CR $>15 \%$ (Figure 5). There was no evidence that Cesarean rates over $15 \%$ correlated to poorer, nor to better, maternal or child mortality rate outcomes.

\section{DISCUSSION}

The main result of this study was that infant and maternal mortality rates show an inverse exponential relation to the rates of Cesarean deliveries across countries. A similar trend has been described by Betrán and colleagues (15) in analyzing 1992-2003 data.

When an exponential regression is assumed, it means that if the target is to minimize IMR and MMR, the optimal Cesarean rate would tend to $100 \%$. Yet, a quadratic model showed very similar goodness-of-fit compared to an exponential model for IMR. If a quadratic regression is assumed, then the optimal Cesarean rates would have an intermediate value, around $27 \%-28 \%$.
The proximity of those two models reflects that the curves were mostly influenced by the more numerous countries with high IMR and low CR (see Figure $1)$; thus, inferences on the effects of higher $\mathrm{CR}$ on mortality rates require additional caution.

Many other statistical models could have been chosen, including local regression techniques or high order polynomial equations. Although sacrificing flexibility, the more straightforward and easy to interpret models were se- lected, since those could be directly used for logical reasoning on health policies.

This study was aimed specifically at CR effects on MMR and IMR; however, many other health and demographic indicators are associated with MMR and IMR (18-20) and could be used as covariates in multivariate regressions. Since their effects usually overlap, the simplest approach took precedence.

In any case, the results challenge the notion that Cesarean rates correlate pos-

FIGURE 2. Maternal mortality rates as a function of Cesarean rates, by country, according to the most recent official data (2000-2009) for 112 countries

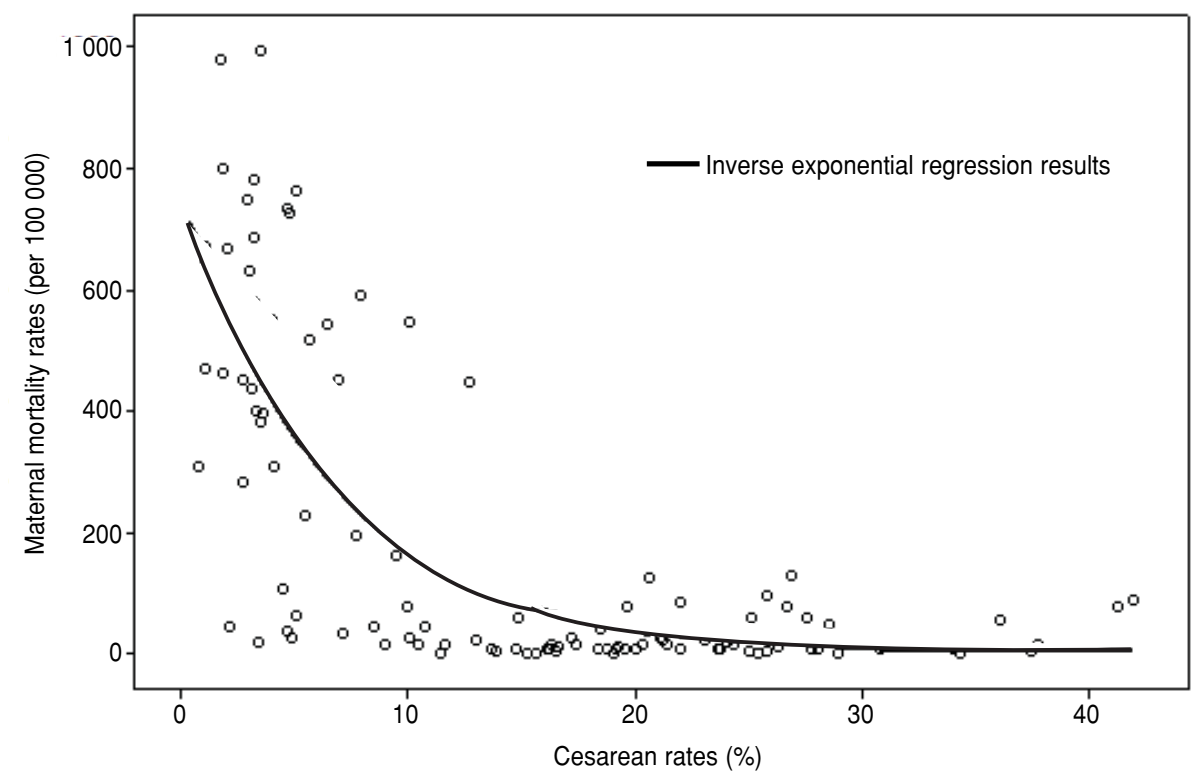

FIGURE 3. Low weight-at-birth rates as a function of Cesarean rates, by country, according to the most recent official data (2000-2009) for 124 countries

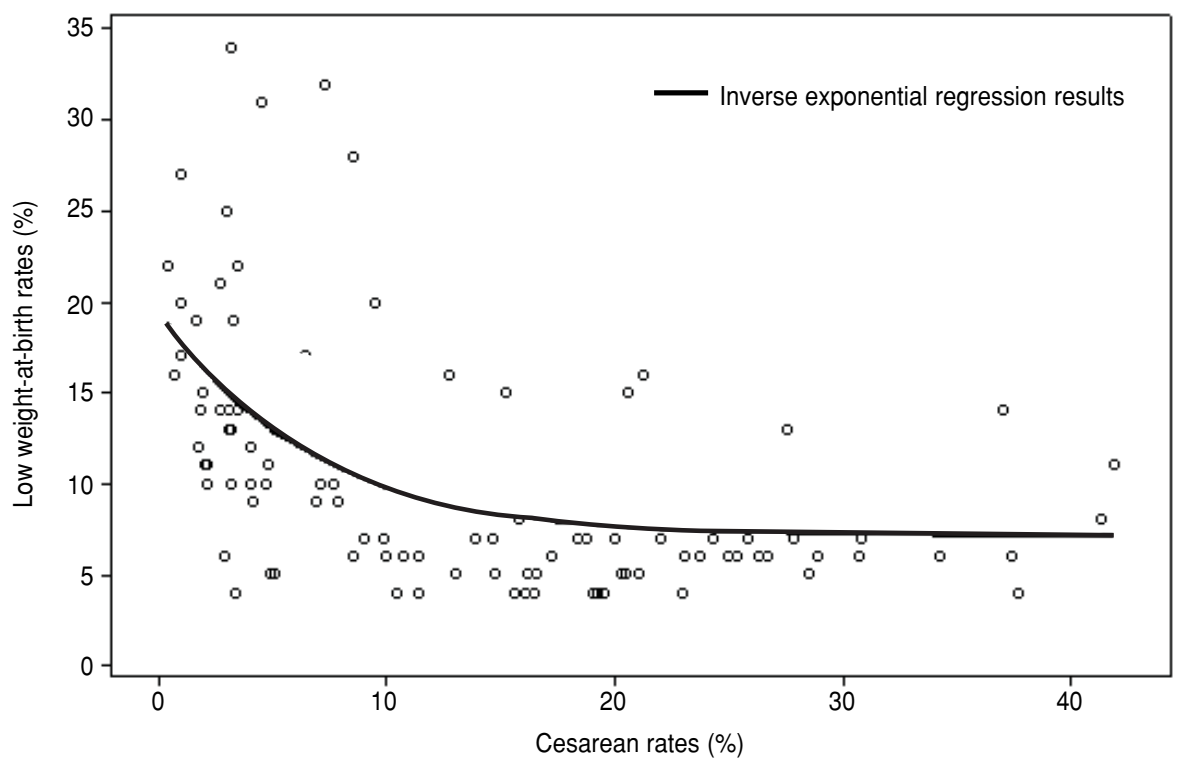


FIGURE 4. Infant mortality rates as a function of Cesarean rates, for countries with Cesarean rates $>15 \%$, according to the most recent official data (2000-2009) for 58 countries

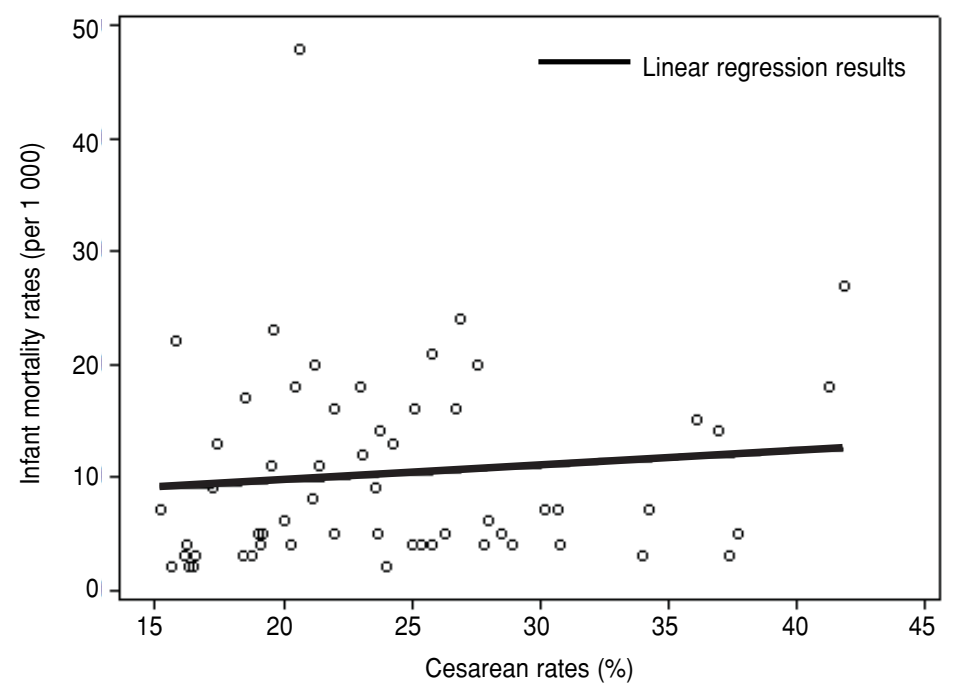

FIGURE 5. Maternal mortality rates as a function of Cesarean rates, for countries with Cesarean rates greater than $15 \%$, according to the most recent official data (2000-2009) for 58 countries

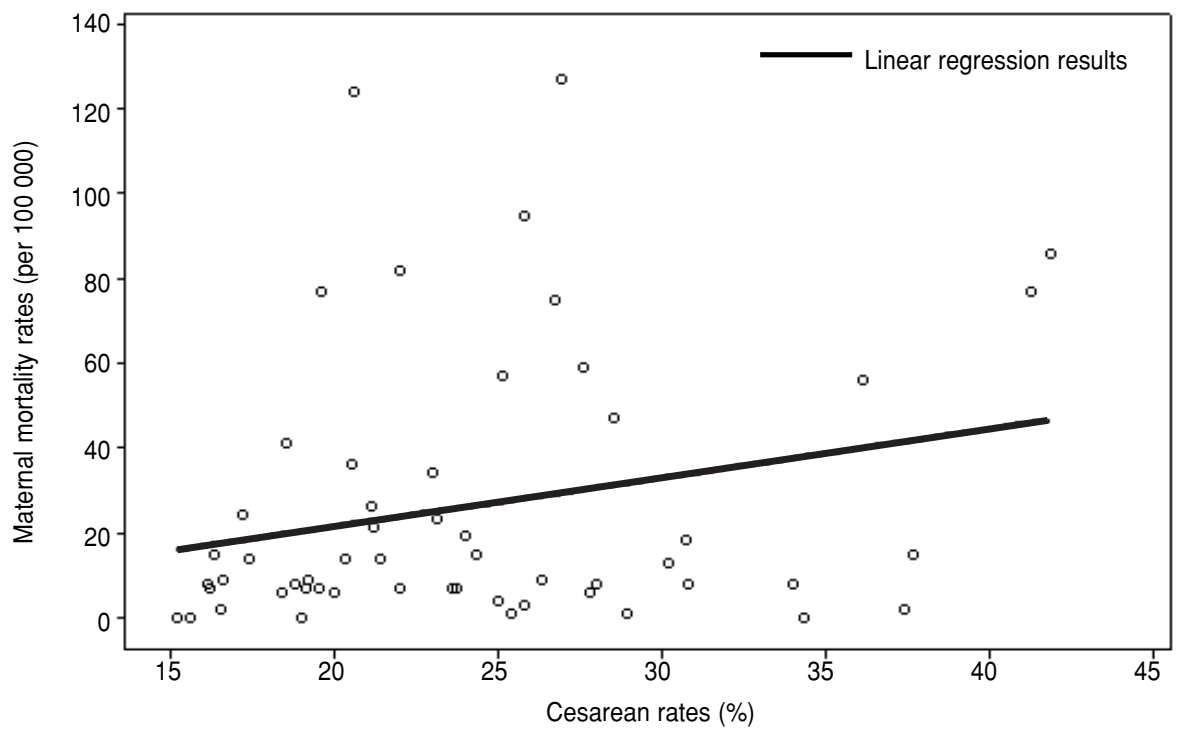

itively to infant and maternal mortality, from a public health perspective. In fact, the lowest IMR and MMR were concentrated in the $15 \%-30 \%$ CR range (Figures 1 and 2), not below $15 \%$ as previously stated $(1,16)$. At rates lower than $15 \%$, CR seems to be a fair indicator of quality of maternal and neonatal care. But over $15 \%, \mathrm{CR}$ appears related to something else, perhaps an indicator of empowerment of women, since it involves the mother's choice of delivery mode (7).

The suspected, elevated infant and maternal mortality rates in countries with Cesarean rates over $15 \%$ were not confirmed by this study. On the other hand, no beneficial effect was shown either. Similar results were found when performing the same analyses on subsamples of countries with CR over $10 \%$, $20 \%$, or $25 \%$. Thus, the original statement that there is no justification for Cesarean rates higher than $15 \%$ (1), strictly withstands the challenge of this ecological transversal study. However, one must consider that "the absence of evidence is not an evidence of absence" (21) and longitudinal studies using more comprehensive outcomes are warranted to further explore this hypothesis. Along those lines, a recent meta-analysis of interventions that reduced CR from an av- erage of $25.8 \%$ to $18.1 \%$ showed no significant beneficial or deleterious effects on infant and maternal outcomes (4).

Also, considering public health expenditures and allocation of resources, higher Cesarean rates may impose greater cost with no collective benefit. Indeed, cost-effectiveness simulations have evidenced that unnecessary $\mathrm{Ce}$ sarean deliveries may have significant impact on health expenditures (22). Nevertheless, no studies have been performed to assess the cost-effectiveness of interventions to reduce Cesarean rates.

In the latest WHO report, Brazil demonstrates the world's 2nd highest CR (41.3\% in 2008), just behind Dominican Republic (41.9\% in 2008). Thus, it remains an interesting case worthy of further investigation. In a recent paper, Volpe and colleagues (19) analyzed the impact of selected indicators on IMR in 27 states in Brazil. In a cross-sectional linear analysis, CR correlated inversely to IMR (R2 $=39.6 \%), P<0.001)$, consistent with current worldwide findings. Considering longitudinal changes from 2000-2006, increases in CR did not correlate significantly to total IMR, but showed a modest effect on late-neonatal mortality rates $(\mathrm{B}=-0.13 ; P=0.005)$. In that study, increasing access to prenatal assistance was, by far, the most important predictor of decreasing IMR.

Excessive medical intervention on delivery resulting in preterm births is a possible path to Cesarean-induced neonatal mortality (23). One could also hypothesize that, since Cesarean rates are indicators of health care quality, countries with high CR would show lower postneonatal mortality rates (i.e., for communicable diseases and water-related deaths), and this would compensate for the hypothetical higher neonatal mortality induced by excessive Cesareans. This would be evidenced by higher neonatal mortality rates and LWR rates in countries with high CR; however, this was not the case in the present ecologic study results. Quite the opposite, neonatal mortality and LWR rates followed very closely the inverse exponential relation to $\mathrm{CR}$ as did the other outcome indicators (data not shown).

However, other factors may determine the occurrence of LWR, such as malnutrition, inadequate prenatal assistance, and tobacco or substance abuse. These could be potential confounders, since they may also be associated to 
IMR, and were not assessed in this study. On the other hand, improvements in early neonatal care related to hospital perinatal assistance during Cesareans may have a compensatory positive effect on neonatal outcomes and mortality rates (23).

Elective Cesarean sections have been associated with higher maternal morbidity compared to vaginal deliveries, but these results focus mostly on the short term $(12,18,24)$. Actually, the long term potential consequences of delivery mode still lack proper assessment. Also, the higher, suspected maternal mortality risks when performing elective Cesareans have not been consistently demonstrated, but rather have yielded conflicting reports $(12,14,18,25,26)$.

This study has limitations due to its ecologic design; thus, individual risks should not be calculated based on data aggregated by countries nor should causal relationships be directly driven from the results. Although the models reached high coefficients of determina- tion for the relation of CR and mortality rates, they may not be appropriate for making predictions on how they might behave were Cesarean rates to rise even more. Many other variables may influence maternal and infant mortality rates, but they were not the focus of this study. Child morbidity was only assessed by low weight-at-birth rates, because no other international official data is available. In addition, global maternal morbidity indicators are not available and could not be assessed by this study.

On the whole, the results of this study point to the need for continuous reevaluation of public health evidence-based recommendations, since evolving health technology may produce significant changes in people's needs and outcomes. Determining the maximum or optimal Cesarean rates is still an open matter, since there is no clear evidence to support a decision. To close this gap, longitudinal studies assessing not only mortality rates, but also more comprehensive morbidity indicators and cost- efficiency analyses for both the short and long term, are needed.

\section{Conclusions}

According to official international data, there is an inverse exponential relation between the proportion of Cesarean deliveries and infant and maternal mortality rates. Very low Cesarean rates $(<15 \%)$ are associated with poorer maternal and child outcomes. Cesarean rates over $15 \%$ were neither correlated to higher maternal nor child mortality, nor to low weight-at-birth. Conversely, higher Cesarean rates are not justified by lower maternal and infant morbidity or mortality.

Interventions to regulate the proportions of Cesarean deliveries should not follow authoritative opinions, as sound or appealing as they may seem. Instead, they should be based on the best available evidence of outcomes, and should be thoroughly and persistently evaluated in terms of their cost-efficiency.

\section{REFERENCES}

1. World Health Organization. Appropriate technology for birth. Lancet. 1985;ii:436-7.

2. Mukherjee SN. Rising Cesarean section rate. J Obstet Gynecol India. 2004;56:298-300.

3. Menacker F, Declercq E, Macdorman MF. Cesarean delivery: background, trends, and epidemiology. Semin Perinatol. 2006;30:235-41.

4. Chaillet N, Dumont A. Evidence-based strategies for reducing Cesarean section rates: a meta-analysis. Birth. 2007;34:53-64.

5. Chalmers BE, McIntyre JA, Meyer D. South African obstetricians' views on Caesarean section. S Afr Med J. 1992;82:161-3.

6. McCourt C, Weaver J, Statham H, Beak S, Gamble J, Creedy DK. Elective Cesarean section and decision making: a critical review of the literature. Birth. 2007;34:65-79.

7. Behague DP, Victora CG, Barros FC. Consumer demand for caesarean sections in Brazil: informed decision making, patient choice, or social inequality? A population based birth cohort study linking ethnographic and epidemiological methods. BMJ. 2002;324:942-5.

8. Weaver JJ, Statham H, Richards M. Are there "unnecessary" Cesarean sections? Perceptions of women and obstetricians about Cesarean sections for nonclinical indications. Birth. 2007;34:32-41.

9. Green JM, Baston HA. Have women become more willing to accept obstetric interventions and does this relate to mode of birth? Data from a prospective study. Birth. 2007;34:6-13.

10. Bernstein PS. Patient-choice Cesarean delivery: really a choice? Birth. 2007;34:89-90.

11. Villar J, Carroli G, Zavaleta N, Donner A, Wojdyla D, Fagundes A, et al. Maternal and neonatal individual risks and benefits associated with caesarean delivery: multicentre prospective study. BMJ. 2007;335:1025.

12. Lumbiganon $\mathrm{P}$, Laopaiboon $\mathrm{M}$, Gülmezoglu AM, Souza JP, Taneepanichskul S, Ruyan P, et al. Method of delivery and pregnancy outcomes in Asia: the WHO global survey on maternal and perinatal health 2007-08. Lancet. 2010;375:490-9.

13. Liu S, Heaman M, Joseph KS, Liston RM, Huang L, Sauve R, et al. Risk of maternal postpartum readmission associated with mode of delivery. Obstet Gynecol. 2005;105: $836-42$.

14. Liu S, Liston RM, Joseph KS, Heaman M, Sauve R, Kramer MS, et al. Maternal mortality and severe morbidity associated with lowrisk planned Cesarean delivery versus planned vaginal delivery at term. CMAJ. 2007;176:455-60.

15. Betrán AP, Merialdi M, Lauer JA, Bing-Shun W, Thomas J, Van Look P, et al. Rates of caesarean section: analysis of global, regional and national estimates. Paediatr Perinat Epidemiol. 2007;21:98-113.

16. The Lancet. What is the right number of Caesarean sections? Lancet. 1997;349:815.

17. World Health Organization. World Health Statistics 2010. Available from: http://www. who.int/whosis/whostat/2010/en/index. html. Accessed 22 June 2010.

18. Villar J, Valladares E, Wojdyla D, Zavaleta N, Carroli G, Velazco A, et al. Caesarean delivery rates and pregnancy outcomes: the 2005 WHO global survey on maternal and perinatal health in Latin America. Lancet. 2006; 367:1819-29.
19. Volpe FM, Abrantes MM, Capanema FD Chaves JG. The impact of changing health indicators on infant mortality rates in Brazil, 2000 and 2005. Rev Panam Salud Publica. 2009;26:478-84.

20. Paul DA, Mackley A, Locke RG, Stefano JL, Kroelinger C. State infant mortality: an ecologic study to determine modifiable risks and adjusted infant mortality rates. Matern Child Health J. 2009;13:343-8.

21. Altman DG, Bland JM. Absence of evidence is not evidence of absence. BMJ. 1995;311:485.

22. Druzin ML, El-Sayed YY. Cesarean delivery on maternal request: wise use of finite resources? A view from the trenches. Semin Perinatol. 2006;30:305-8.

23. Barros FC, Victora CG, Barros AJ, Santos IS, Albernaz E, Matijasevich A, et al. The challenge of reducing neonatal mortality in middle-income countries: findings from three Brazilian birth cohorts in 1982, 1993, and 2004. Lancet. 2005;365:847-54.

24. Wax JR. Maternal request Cesarean versus planned spontaneous vaginal delivery: maternal morbidity and short term outcomes. Semin Perinatol. 2006;30:247-52.

25. Vadnais M, Sachs B. Maternal mortality with Cesarean delivery: a literature review. Semin Perinatol. 2006;30:242-6.

26. Geller EJ, Wu JM, Jannelli ML, Nguyen TV, Visco AG. Maternal outcomes associated with planned vaginal versus planned primary Cesarean delivery. Am J Perinatol. 27:675-83.

Manuscript received on 31 July 2010. Revised version accepted for publication on 3 February 2011. 
RESUMEN Objetivo. Correlacionar los datos oficiales internacionales sobre las tasas de parto por cesárea con las tasas de mortalidad materna e infantil y con la tasa de bajo peso al nacer, y someter a prueba la hipótesis que sostiene que una tasa de cesáreas mayor de

Correlación de la tasa de cesáreas con las tasas de mortalidad materna e infantil: estudio ecológico basado en datos oficiales internacionales
$15 \%$ se correlaciona con tasas de mortalidad materna e infantil más elevadas.

Métodos. Los análisis se basaron en los datos oficiales más recientes disponibles (2000-2009) de 193 países. Se compararon modelos exponenciales con modelos cuadráticos para hacer un análisis de regresión de las tasas de mortalidad infantil, neonatal y materna, así como de las tasas de bajo peso al nacer, respecto de las tasas de cesáreas. En los países con una tasa de cesáreas mayor de 15\% se efectuaron análisis de regresión separados.

Resultados. En los países con una tasa de cesáreas menor de 15\%, las tasas más elevadas se asociaron con tasas de mortalidad infantil, neonatal y materna más bajas, y con una tasa de bajo peso al nacer más baja. En los países con una tasa de cesáreas mayor de $15 \%$, la tasa de cesáreas no tuvo una asociación significativa con las tasas de mortalidad infantil o materna.

Conclusiones. Existe una relación exponencial inversa entre las tasas nacionales de partos por cesárea y las tasas de mortalidad infantil o materna. Las tasas de cesáreas muy bajas (menores de 15\%) se asocian con un peor pronóstico materno e infantil. Las tasas de cesáreas mayores de $15 \%$ no se correlacionaron con una mortalidad materna e infantil más elevada ni con bajo peso al nacer.

Palabras clave Mortalidad infantil; mortalidad materna; mortalidad neonatal; cesárea; peso al nacer. 